\title{
Negotiating the rules of engagement: exploring perceptions of dance technique learning through Bourdieu's concept of 'doxa'
}

Rachel Rimmer*1

Department of Contemporary Arts, Manchester Metropolitan University in Cheshire, UK.

(Received 10 $0^{\text {th }}$ August 2015; accepted 20 $0^{\text {th }}$ November 2015; re-submitted with revisions on $10^{\text {th }}$ January 2016; returned on $9^{\text {th }}$ February 2016; re-submitted with further revisions on $16^{\text {th }}$ April 2016; returned with minor revisions on $17^{\text {th }}$ June 2016; re-submitted with revisions on $12^{\text {th }}$ July 2016; returned with minor revisions on $30^{\text {th }}$ January 2017)

This article presents the findings from a focus group discussion conducted with first year undergraduate dance students in March 2015. The focus group concluded a cycle of action research during which the researcher explored the use of enquirybased learning approaches to teaching dance technique in higher education. Grounded in transformative and constructivist learning perspectives, such approaches attempted to develop students' reflective thinking skills, with a view to enabling them to become active agents of their learning in dance technique. The focus group aimed to explore students' responses to the teaching approaches used. The author examines the data by drawing on Bourdieu's (1977) concept of 'doxa' to discuss how perceptions and expectations of dance technique may be constructed, both on the part of the students and the teacher. The notion of doxa is used as a lens to reflect on some of the challenges around attempting to deconstruct such expectations.

Keywords: doxa; dance technique; pedagogy; enquiry-based learning; action research; reflexivity

\section{Introduction}

This article has emerged from an ongoing teacher-research enquiry that is underpinned by the desire to enable undergraduate students to become reflective, active agents of their learning in dance technique whilst enhancing my own awareness of my teaching practice. My aspiration to develop a reflexive understanding of myself as a teacher locates this research within transformative learning perspectives, a theory of education that emanates from the work of Mezirow (2009). Graham Cagney $(2014,789)$ suggests that learners engaged in transformative processes 'work through experiences that challenge his or her tacit, taken-for-granted assumptions, beliefs, values and expectations'. Strong engagement with critical self-reflection enables the researcher to become more

$1 *$ Email: r.s.rimmer@mmu.ac.uk 
'open, transparent, flexible, authentic and capable of change' (ibid). To instigate change, Brookfield (1995) proposes that teacher-researchers should view their practice from four different perspectives, or 'lenses', one of these being through the eyes of their students. To do this, in March 2015 I conducted a focus group discussion with seven students who had participated in a cycle of action research between January and March 2015. The action research explored the effects of introducing teaching methods that foregrounded an enquiry-based approach to learning dance technique.

This article presents the findings from this focus group discussion, contextualised by ideas related to traditional paradigms of western dance technique pedagogy, and Bourdieu's sociological concept of 'doxa' (1977). Bourdieu (1977, 164) states that 'doxa' refers to that which is 'taken for granted', whereby 'the natural and social world appears as self-evident', that which 'goes without saying because it comes without saying' (167). According to Deer (2012, $114-115)$ Bourdieu's concept of doxa relates to a 'social arbitrariness' that is reproduced in 'social institutions, structures and links as well as in minds and bodies, expectations and behaviour'. These ideas will be used to explore essentialist or 'doxic' understandings of the role of dance technique teacher and student. The extent to which doxa has contributed to the formation of prevailing discourses that surround what it is to be both a teacher and a student of dance technique will be examined. Furthermore, in considering 'what needs to take place in order to break free from it' (Deer 2012, 114), the paper will consider the extent to which the use of enquirybased learning methods can be effective in deconstructing the doxa.

\section{The 'taken for granted' paradigms of dance technique pedagogy}

As an academic in the early stages of my career, over the last four years I have experienced a series of what Tripp (1993) would describe as 'critical incidents', leading me to question my role as a teacher of dance technique. It is no coincidence that this heightened sense of criticality developed around the same time I was undertaking a teaching qualification for higher education. While studying for this qualification, I became interested in the nature of the questions that a particular group of first year students were asking during our technique classes. During my 
demonstrations of the technique material, students' questions were often directed towards understanding what my body was doing and not necessarily how or why and many individuals articulated a desire to get the movement 'right'. Although I recognised that these questions were coming from a genuine place of curiosity, the emphasis on getting the movement 'right' or 'wrong' led me to contemplate what the students were identifying as important aspects of learning dance technique, and furthermore, the aspects of my teaching that I may have been taking for granted.

\section{'Rights', 'wrongs' and closed systems of learning}

Dyer (2009) explores the idea of 'rights' and 'wrongs' in relation to dance technique; she suggests that perceiving learning from perspectives of right and wrong could be associated with western educational ideologies. A student pursuing 'rights' and 'wrongs' positions the teacher as a figure of authority and judgement, yet 'the desire to be right in order to prove one's self worth can overshadow meaningful inquiry' $(2009,118)$. Aceto $(2012,14)$ states that new undergraduate students enter her dance technique classes "preferring the satisfaction of "getting it right" and express discomfort when details about a phrase are left unanswered by an instructor.' It cannot be ignored that teacher demonstration is an integral part of learning a motor skill such as dance technique as acknowledged by Stanton $(2011,87)$ who states that in fostering learner autonomy in technique learning, 'a delicate balance is in operation...care needs to be taken not to dismiss the effectiveness of observing an expert'. However, perhaps it is inevitable that less experienced students will form opinions about what is 'right' or 'wrong' based on observing a teacher's example. To enable students to become less reliant on the teacher, the teacher must assist them in being able to independently judge the quality and understanding of their own technique.

This idea was discussed during a 2006 Higher Education Academy Palatine seminar, which focused on the role of dance technique in UK higher education. Here, the need for degree programmes to rely less on teacher dependent learning environments in favour of student-centred learning was highlighted (Stevens 2006). This idea is particularly pertinent when considering the traditional notion of the dance technique class as a teacher-led environment where students aim to imitate 
the movement examples provided by the teacher, whilst receiving feedback on the 'correctness' of their replication. Resonating with these ideas, Hanstein (1990) shared a vision for dance education to operate as an open learning system that foregrounds discovery and change. She argued that when dance is 'taught only as the replication of steps, as a closed system in which the ends are preset and the outcomes tightly controlled' $(1990,56)$ educators do not 'promote the kind of inquiry, imaginative thinking, and discovery necessary for ordering our experience and making sense out of our lived world' (ibid). Twenty years later, Bannon (2010) used Hanstein's ideas as a lens through which to view higher dance education in the UK. With reference to dance technique, Bannon suggests that individuals should be 'presented with the opportunity to achieve knowledge that is particular' (50). However, Stevens (2006) states that many teachers in higher education report a 'mismatch' between students' expectations of dance technique and teachers' style of delivery. Thus, it could be said that in order to understand how to enable students to begin the process of discovering particular knowledge, both student and teacher must navigate their way through a complex web of expectations, but how easy is this when operating within the constraints of a 'doxic' understanding of dance technique?

\section{Teacher/student relationship: a 'doxic' understanding}

Dance scholars have discussed some of the challenges associated with managing the transition to higher education for first year students, particularly where dance technique is concerned (Stevens 2006, Schupp 2010, Dryburgh and Jackson 2016). Such research has found that the teaching approaches used in higher education often differ greatly to a student's prior learning in dance technique; the emphasis on holistic approaches to working with the body, reflection and independent learning may present challenges for some individuals, depending on past experience and their ability to adapt to new ways of working. Altering one's perception of the teacher as the provider of technical dance knowledge to that of a facilitator of individual knowledge can be a radical shift for some students. Bourdieu's concept of doxa could be used to explain why such difficulties exist. According to Maton (2012, 56) social agents are attuned to the doxa of a given field when they have a feel for 
the 'unwritten "rules of the game"' or 'underlying practices within that field.' This is dependent upon what Bourdieu describes as one's 'habitus', the dispositions that are 'structured' by 'one's past and present circumstances, such as family upbringing and educational experiences.' (Maton 2012, 50) When the habitus comes into contact with a particular field, certain types of behaviour or 'practice' are produced and these social practices are 'characterized by regularities' (ibid, 49) within the field.

An example of the habitus at work in a field specific to dance education can be found in the work of dance scholar Pickard $(2013,2015)$. Pickard has explored the accepted regularities of the ballet world by examining the extent to which student dancers in non-residential ballet schools in England conform to the 'rules of the game' where fixed ideals in relation to body shape and size are concerned. She states, 'The young dancers gain a 'feel for the game' (Bourdieu 1990) through engagement with the rules...The belief in the body becomes, in Pierre Bourdieu's terms, a core part of a ballet dancer's habitus.' $(2013,15$ - 16) Similarly, this 'feel for the game' can be explored within the field of the university dance technique class, where it could be said that there is an implicit assumption that the teacher directs and it is this implicit assumption that this paper attempts to explore. The idea of teacher direction in dance technique has been examined by a number of dance scholars who have investigated traditional pedagogical paradigms associated with dance technique (Lord 1981, Hanstein 1990, Stinson 1993, Smith 1998, Stevens 2006). Furthermore, to reconceptualise the power relationship between dance technique teacher and students, scholars have explored the use of alternative pedagogical models by drawing on ideas grounded in critical pedagogy, constructivist and somatic learning perspectives (Fortin 1998, Green 1999, Enghauser 2007, Råman 2009, Dyer 2009, 2010, Stanton 2011, Aceto 2012, Dryburgh and Jackson 2016).

With further reference to Bourdieu (1977), it could be argued that the traditional formality of the dance technique class has established a 'doxic' understanding of the teacher/student relationship. According to Bourdieu, a doxa can be apparent within a power relationship, where the authoritative and the subservient play out their roles without question. Social agents understand their 
position within the 'field' and their performance complies with the rules of social convention. Arguably, this understanding subsequently constructs codes of behaviour, which determine how the teacher expects to teach and how the student expects to learn, adhering to what Bourdieu calls 'the doxic mode' (164). The doxa manages what can be understood and consequently establishes an understanding of how dance technique constructs its position, resulting in an undisputed doxic agreement of negotiated and agreed expectations, both on the part of the teacher and the student. Indeed, the very nature of the term 'dance technique' may have contributed to this doxic understanding of agreed expectations, some of which may have been achieved through the perceived differences between dance technique and other less 'formal' areas of dance education.

\section{Enquiry-based learning and constructivism}

In the pursuit of facilitating first year students to become reflective, active agents of their learning in dance technique, this action research study focused on exploring the effects of introducing teaching methods that foregrounded an enquiry-based approach to technique learning. Hutchings (2007) describes enquiry-based learning (EBL hereafter) as an approach that encourages students to engage in active learning as opposed to passively accepting information delivered by the teacher. EBL encourages a self-directed approach to learning; it is the responsibility of the student to address scenarios that have been created by the teacher. According to Hutchings $(2007,12)$ 'enlightenment only truly comes to the learner when she or he takes possession of the process of discovery'. As a result 'learning outcomes are more likely to become intellectually embedded: what we discover, we retain' (ibid). Furthermore, as EBL requires the student to take the initiative, and contemplate different possibilities, a range of intellectual and social skills are developed including critical thinking, reflection, self-criticism and autonomous thinking $(2007,13)$.

The student-centred nature of EBL situates it within constructivist learning perspectives. Constructivism positions learners as active constructors of meaning and knowledge as opposed to passive recipients of information (Marlowe and Page 1998). According to Hershberg (2014) the origins of constructivism date back to the early 1920s and can be found in the work of the developmental psychologist Piaget 
(1896 - 1980) who conducted research on the development of children. Piaget discovered that children construct knowledge through creating meaning from their interactions with the world. The child then amends their worldview as they encounter new information. Bruner (1960) developed these ideas by suggesting that teaching instruction should provide learners with opportunities to actively construct their own knowledge by building on existing knowledge and reflecting on this process. According to Marlowe and Page (1998), constructivism is not about privileging the amount of information a student can memorise, but rather offering students the autonomy to construct individual meaning by investigating in the 'context of a problem, critical question, issue or theme' (11). The teacher is viewed as a facilitator to this process, guiding the student through the process of investigation and discovery.

An enquiry-based approach to teaching dance technique requires the teacher to create scenarios in which students can actively explore and critically engage with movement phenomena both kinaesthetically and cognitively. Such processes may involve collaborative partner work (Råman 2009), problem-solving activities (Stanton 2011, Aceto 2012) and analysis through group discussion and physical exploration (Dryburgh and Jackson 2016). The action research study being discussed in this paper drew on some of the teaching approaches explored in those studies referenced above. For example, students were invited to take a problem-solving approach to investigating technical movement concepts by working with a partner and identifying what part of their anatomy initiated a particular movement. Students were also invited to create short phrases based on technical movement principles including rotation, control of centre and transfer of weight (Kimmerle and Cote Laurence 2003). In addition, they were given opportunities to participate in improvisation activities as a way to explore movement possibilities and to test their knowledge of technique class materials, a method I had previously researched prior to embarking on this cycle of action research (Rimmer 2013). Alongside such practical tasks, students were invited to reflect on their experiences of these methods by engaging in class discussions and writing journal entries.

\section{Action research}


According to McAteer (2013) action research is built on the premise of identifying an issue in one's teaching practice and exploring ways to address this issue through a self-reflexive process involving a series of iterative cycles. Giguere (2015) states that action researchers engage in a 'cycle of observation, questioning, data gathering, analysis, and action planning that results in a new observation which will then be questioned' (18). The action research took place over a series of eleven weekly technique classes, which were attached to a first year module called Dance Practices One (DP1). DP1 combines three assessed elements, which are a choreographic assignment, classes in dance technique and a reflective essay. It should be noted that all modules within the undergraduate degree programme position dance technique as one assessed element within modules that have a broader performance focus; this programme structure means that technique does not stand alone as a singular module, but is instead seen to underpin other choreographic/performance practice.

At this point in my teaching career, I was taking an integrated approach to dance technique, blending principles originating from 'formalised' modern dance techniques (Cunningham, Hawkins) with other post-modern release-based movement ideas. This blended approach to teaching technique was reflective of the integrated nature of my own dance training, an approach to technique that Diehl and Lampert (2010) suggest many teachers adopt. However, as my research in this territory has progressed, my classes now focus more entirely on exploring postmodern releasing principles; the full rationale for this goes beyond the remit of this paper, but my developing interest in this approach is directly related to my discovery that release-based techniques appear to naturally accommodate the constructivist and somatic orientated teaching approaches that I have increasingly become more engaged with.

During the action research process, I wrote weekly journal entries to record my immediate reflections on each session. These reflections were a valuable method for documenting my thinking, and over time, recurring themes and questions about my practice began to emerge. These ideas then assisted me in forming questions for the focus group discussion, which took place at the end of the action research cycle. As previously discussed, the aim of the focus group was to 
deepen my understanding of my teaching practice by gaining an insight into students' perceptions of the enquiry-based, constructivist teaching methods that had been used throughout the action research. The findings from this would then be used to inform a subsequent cycle the following academic year. This second cycle of action research was conducted between January and March 2016 with a different student cohort. Cycle two built on the findings from cycle one by exploring themes related to dialogue and reflective learning in dance technique; however, a discussion of the findings from the second cycle exceeds the scope of this paper.

\section{Ethical considerations}

All students were informed about the action research before it commenced and were given the opportunity to decide whether they gave their consent to participate. Fortunately, all students were happy to contribute towards this research and were extremely generous in the process of doing so. Since the first year students were separated into two cohorts, DP1 had two parallel runs, one delivered by me and the other delivered by my colleague, who I will refer to as 'colleague A'. Colleague A was aware of my research intentions, and although she was not conducting formalised action research with her group, in order to try and create parity between the two cohorts we decided that she would mirror some of the same enquiry-based learning approaches as me. Unexpectedly, this arrangement with Colleague A provided me with many valuable opportunities to engage in dialogue with her about my ideas, and I am extremely grateful for her continuing interest in my research.

\section{Focus group as a method in action research}

Holland and Elander (2013, online) suggest that a focus group is a useful data collection tool when the project is about investigating shared understandings, or group processes, rather than one individual's understandings or beliefs. Due to the shared environment of the dance technique class, a focus group would be a useful way to engage in dialogue with my students about their experiences of my teaching. Seven participants were selected based on gender, age and programme of study, with the idea of gathering a range of different perspectives. The discussion 
participants (using pseudonyms) were:

- Roxanne*: female, age 21 and studying Dance with English

- Ruth*: female, age 19 and studying Dance

- Sarah*: female, age 19 and studying Dance

- Rory*: male, age 19 and studying Dance

- Kiera*: female, age 20 and studying Dance with English

- Poppy*: female, age 19 and studying Dance

- Callum*: male, age 18 and studying Dance

During the discussion, I adopted a researcher/moderator role that according to Savin-Baden and Howell Major (2013) involves actively contributing by asking general then specific questions, and probing deeper when necessary; this dynamic between facilitator and participants also resonates with the relationship between teacher and students in an EBL environment. Savin-Baden and Howell Major (ibid) suggest that structuring the discussion like this assists with 'the flow of the conversation' (380) and 'allows interviewees some room to explore ideas' (ibid). According to Holland and Elander (2013, online) it is the role of the moderator to reflect the group consensus by regularly summarising what has been said, and pointing out where participants appear to agree or disagree.

\section{Power relationships}

When discussing the relationship between interviewer and interviewee in action research projects, McAteer (2013) points out that in teacher-led research, issues of power may 'emanate from teacher-pupil or staff hierarchy situations' (76) and this must be taken into consideration by the researcher. Although McAteer's point is made in relation to interviews, the same idea still applies to focus groups. Therefore, I chose to point out to the students that as their teacher, I recognised an apparent hierarchical relationship, but regardless of this, it would serve the research most effectively if they were able to give honest responses to the questions. In addition, at some points during the discussion, my 'teacher' status led me to become 
anxious about what the students were going to say about my teaching. There were occasions when I found myself resisting probing further on certain subjects in an attempt to protect myself, demonstrating another challenge around my perceived status. It is possible that these issues could have been avoided had a more neutral person facilitated the discussion, but this arrangement would not have felt appropriate since the aim of the activity was to understand more about my teaching practice by engaging with it through the eyes of my students. Both of these tensions highlight the complexities of teacher-led research and acted as a reminder that the students might be guarded in their discussion responses; this was something that I took into consideration when analysing their comments at a later date.

I would also like to point out that for the second cycle of action research, rather than selecting individuals myself, students were invited to volunteer for the focus group. My rationale for this was based on the idea that students may have felt they had greater ownership over the decision to contribute towards the research, rather than feeling obliged to participate because the teacher asked them to.

\section{Data analysis}

The discussion was filmed and subsequently transcribed. The transcribing process enabled me to familiarise myself with the data, giving me the opportunity to immerse myself within it. McAteer (2014) and Savin-Baden and Howell Major (2013) suggest this is key when attempting to identify units of meaning in qualitative data. I then used a colour-coding approach to aid recognition of recurring themes and areas of interest. To further excavate meaning, a thematic analysis approach was used, which according to Savin-Baden and Howell Major $(2013,440)$ 'provides a general sense of the information through repeated handling of the data'. Thematic analysis enables the researcher to 'get a feel for the whole text by living with it' (ibid) and to 'rely on intuition and sensing, rather than being bound by hard and fast rules of analysis' (ibid). This approach inevitably requires the researcher to be reflexive in their analysis of the data, and to recognise their own subjectivity in the handling and interpretation of it. As Etherington (2004, 31 - 32) states, the reflexive researcher must 'acknowledge how their own experiences and contexts (which might be fluid 
and changing) inform the process and outcomes of inquiry.' This is something I tried to be aware of when developing a discourse around the discussion responses.

\section{Focus group discussion findings}

\section{A 'doxic' understanding of dance technique}

To begin, individuals were asked to consider what the term 'dance technique' brought to mind and the images it evoked. Here, it is useful to make further reference to the notion of a doxic understanding implied by the very term 'dance technique'; what are the associations that students make with this term? Further, what are the expectations that they attach to it? Roxanne initiated discussion by saying 'pointed toes' and Rory added the following comment:

Straight away, I'd say ballet, as a technique. I think it just stands out more then anything else. Like contemporary is so broad, like you could go Graham, Cunningham, even though they're all a little bit different in so many ways kind of thing. Ballet's kind of the grounding...(Rory 20.3.2015)

Rory appears to identify ballet as being the pinnacle of dance techniques; his understanding seems to be that other codified dance techniques, what he refers to as 'contemporary', find their 'grounding' in ballet. He concluded his response by stating 'Personally I just don't like being set something so rigid.'

Poppy responded to this question by referring to her practice in my technique classes and comparing this with her experiences in a colleague's (referred to as Colleague B) choreography classes, which involved improvisation:

...in our technique classes, that's what I did at college, so it feels natural to me, the precision of it...In your technique class, it's kind of normal, I feel comfortable with it. And it'd be juxtaposed with [Colleague B's] classes where l'd just be thrown completely out of my comfort zone. But I think I've grown as a dancer. (Poppy 20.3.2015).

Poppy's description of her experiences in dance technique suggests familiarity, a place where she is in her 'comfort zone' as opposed to out if it, as she seems to be in choreography classes. Like Poppy, Sarah compared her experiences in technique with choreography stating: 
[in choreography] you feel like you can't really go wrong with it, because it's so broad, and like, anything you do is OK. Whereas in technique classes, it's this is what you do, this is how you do it. And I think with me, my confidence is better when I'm choreographing, because it's something that l've come up with myself, dya know what I mean? Instead of it being so set. (Sarah 20.3.2015).

Rory, Poppy and Sarah all used words such as 'rigid', 'precise' and 'set' to describe their experiences in dance technique, implying a sense of inflexibility. Even though not all of these responses appear to make direct reference to my technique classes, this perception of dance technique as a fixed entity contradicts the kind of environment that I was attempting to establish through the use of EBL approaches. My aim had been to avoid making exercises seem 'set' by emphasising the idea that within each technique exercise, there were opportunities to play and explore. Inspired by the research of Stanton (2011), in most exercises, students had been encouraged to test different movement possibilities and to reflect on this process of trial and error. This approach aligns with ideas associated with EBL, which according to Hutchings $(2007,13)$ aims to convey the notion that 'there are often no straightforward, ready-made answers' and in fact any one scenario could evoke a range possible outcomes.

The students' responses contradicted the perception I had formed of my own teaching. Although the students helped me to understand how they were perceiving 'dance technique' as a concept, and to a degree, my delivery of it, their responses have since led me to reflect on whether I could be more experimental with the teaching approaches being used. Here, it is important to recognise that since this was the first cycle of action research, it is likely that I was being somewhat tentative with regard to disrupting what I perceived to be the cultural norms of the dance technique class too dramatically. Bourdieu (1977) suggests that when social agents are attuned to the doxa of a given field, they have a feel for the unwritten 'rules of the game'; they are 'at home' like a 'fish in water'. When the habitus and the field clash, it suggests that the agent does not understand the rules and thus feels like a 'fish out of water'. In challenging my own expectations of myself as a teacher and the students' expectations of dance technique, the rules of the game were being shifted. Testing the boundaries of my authority in this way felt like a risk; the first year students were managing the transition to university and experiencing new ways 
of working, and I was also in the early stages of my academic career, adapting to my role as an academic. On many occasions during this first cycle of action research, I can remember feeling concerned that we could all end up feeling like fish out of water. As I have gained more experience and become more confident, this is something I have continued to reflect on, and much like Poppy, I have become more willing to step outside my own comfort zone.

The responses highlight some of the challenges around enabling students to depart from preconceived ideas about dance, in this instance, dance technique. It became apparent that students' expectations, both of their own behaviour and that of the teacher are likely to be constructed by their prior learning experiences. As Deer $(2012,115)$ points out, 'Doxa refers to pre-reflexive intuitive knowledge shaped by experience, to unconscious inherited physical and relational pre-dispositions.' It is through these 'pre-dispositions' that an individual's doxic understanding could be formed. As this understanding 'comes without saying', students are unlikely to question it unless they are given the opportunity to do so. Perhaps then, it is the teacher's responsibility to stimulate this questioning process, as demonstrated in a study by Dyer (2010), which provided students with the opportunity to reflect on their own socio-political values in relation to their experiences of being dance technique students. Similarly, before embarking on this research study, I too had not considered my own doxic understanding of my role as teacher. Being encouraged to confront and question my own unconscious pre-dispositions about dance technique education has initiated a reflexive process for me, leading me to reconsider my understanding accordingly.

\section{Viewing 'dance technique' in isolation}

The students had already begun a process of drawing comparisons between different areas within the dance programme. Poppy's response had steered the conversation towards comparing experiences in dance technique with choreography and improvisation. Later in the discussion, she stated how upon arriving to university she "hated improv. Make me improv, I'd stand there and go "no", but if I've got a fixed dance, I'll do it beautifully'. Similarly, Kiera said that for her, even though she found technique challenging, she felt 'more comfortable with technique 
[than improvisation] because you know what you're doing, like everybody's doing the same sort of thing'. Roxanne stated that technique was an important way to understand safe dance practice, and that the work done in a technique class should support the dancer in improvisation:

I think it's making sure that you're doing your movement safer...So like even when you're improvising, because you've got that base of technique, you know that when you bend your knees to know that your alignment isn't all off. So even if you're not confident in it, you'd be more aware of your body. (Roxanne 20.3.2015)

This separation between dance technique and improvisation was another revelation for me, demonstrating that regardless of each student's preference for one over the other, there was a strong feeling that these two entities did not necessarily sit together. Since I had been utilising improvisational methods in my own technique classes, these opinions came as a surprise to me. Of course, improvisation comes in many forms, and will inevitably function in different ways depending on the context in which it is being utilised (choreography, technique, somatic practice), but what this data appears to demonstrate is that the participants naturally aligned improvisation with 'experimental' choreographic contexts, and not necessarily with dance technique.

Much like students construct their understanding of dance technique based on prior learning experiences, their perceptions of improvisation appear to be formed in relation to this perception of dance technique. Even by virtue of their labels, it could be said that 'technique' and 'improvisation' are positioned in opposition, but how useful is this categorisation when attempting to enable students to move away from fixed perceptions of dance education? In relation to this idea, educationalists Alexander et al. (1992) question the division of subjects in schools by suggesting it is inconsistent with a child's view of the world. They argue that children 'must be allowed to construct their own meanings and subject division involves the imposition of a received version of knowledge.' (21) According to Alexander et al. (ibid) 'it is the wholeness of the curriculum which is important'.

Perhaps then, the same could be said of the position of dance technique in higher education. Compartmentalisation of dance 'subjects' may not be helping 
students to draw connections across the different areas of their education and to form a more holistic view of their learning in dance. Compartmentalisation could lead to a different doxa being constructed in relation to each area, or 'field' of learning. Each 'field' retains its own set of unwritten rules, which determine how the social agents of that field behave. What is more, by making my technique classes the central topic of discussion for the focus group, I too may be guilty of viewing dance technique in isolation from other areas of the students' learning, thus perpetuating the doxic understanding. Perhaps I needed to make the connections between choreography, improvisation and technique more explicit for the students rather than assuming they had done this automatically. This is a realisation that I have continued to reflect on as my research has developed.

\section{Teacher's 'style': an underlying doxa?}

During the discussion, I reminded the students about their encounters with improvisation in my technique classes and some individuals did then acknowledge that there were different types and 'styles of improvisation'. However, some students felt that these 'styles of improvisation' were dependent upon who was teaching them and what that teacher's individual 'style' was. This discussion around teacher's 'styles' continued when I asked the group to reflect on a task I had delivered, which involved working collaboratively to create a short phrase based on the movement principle rotation. In response to this, Rory said:

Because it [the task] was set by yourself, we kind of knew which way to do it. Like if [Colleague A] said make a dance about rotation, it'd be different. Same with [Colleague B]. So I think it depends what class it is and who's teaching it. It's similar to your style, the phrase we did, but then we kind of made it our own. (Rory 20.3.2015)

Poppy picked up on Rory's comment by stating:

We go into different classes with kind of different heads on. I don't know, you all have completely different styles, and you kind of go in with that lecturer's kind of style in you. (Poppy 20.3.2015) 
I had not knowingly pointed towards a particular movement 'style' that I was hoping the students would attempt to imitate in their own phrases and therefore, these comments were unexpected. However, what they reveal is that my technique classes are evidently providing the students with a vocabulary of movement that they recognise as a certain 'style', and this 'style' is different to that of other teachers. What is not clear to me is whether the students were referring to the aesthetic style of the dance techniques that I was drawing upon, or my own stylistic execution of these techniques; of course these two entities are virtually impossible to pull apart, which further complicates the matter.

It is, however, inevitable that a first year student would attempt to replicate the teacher's dance 'style' since they have not yet been exposed to the range of techniques and movement ideas that a more advanced student would have been, and as a result they have had less opportunities to develop their own individual movement 'style'. Therefore, it would seem that less experienced students work with the vocabulary at hand, imitating the teacher, or approaching the task in a way they assume the teacher expects them to.

\section{Rules of engagement: negotiating the doxic agreement}

Rory's comment, 'Because it was set by yourself, we kind of knew which way to do it' implies that from his perspective, as his teacher, I am establishing rules of engagement that enable him to complete the task, but on my terms. From my perspective, I do not consider myself to be establishing rules, but rather inviting the students to play within a framework of possibilities. I would like to say that I had no expectations regarding the way each student should approach the task, but this would not be entirely true. For example, if a student chose to stand still for a minute and explore the internal rotation of their breathing, would I find this to be an appropriate response to the task? Although conceptually interesting, would I be able to assess their technical dance ability through this response in the same way as a response incorporating large weight shifts, turns or jumps? These are questions that require further consideration when attempting to integrate choreographic activities into the technique class. 
Although I am not aware of having verbally articulated specific rules of engagement regarding an expected way of approaching the task, clearly, through the verbal and embodied dialogue between my students and me, some rules have been established, and thus it could be said that we enter into an unconscious doxic agreement with each other. Indeed, Poppy's comment about arriving at each class with 'different head[s] on' indicates that she perceives there to be different doxic agreements from one class to another, and each agreement invites a particular kind of practice. Consequently, it seems that students engage in a process of negotiating one doxic agreement to another, as they move from one dance class to another. Even in my attempt to resist conforming to the traditional paradigms of dance technique pedagogy through the use of enquiry-based approaches, it seems I am responsible for imposing a particular system of learning onto my students, a system that encompasses its own set of rules and practices. Indeed, this is an important idea to reflect on as I consider the extent to which my chosen teaching approaches have enabled both the students and me to depart from such paradigms.

\section{Making connections}

It is important to acknowledge that within this discussion, some students did state that their overall experience of dance at university had demanded more of them than their experiences prior to university. The general consensus seemed to suggest that dance as an art form was much broader at university, and had even caused some individuals to question the way they would define the term 'dance' based on their new knowledge. The students also agreed that the level of dance technique required of them at university was much more technical and complex than previously experienced, and some students stated that the movement concepts being studied were new to them. In order to work at this more advanced level, some individuals suggested that they had been required to build on existing technical knowledge. For example, Ruth described how some of the principles of contemporary dance technique were very different to her training in Latin and Ballroom dance, but regardless, she was able to make connections between the two: 
See, my technique's totally different. Like with me, l'd never even heard of any of these. But, from the technique I've done, I can relate to certain things. Like with the turnout. Obviously in Latin, you've naturally got a slight turnout...People don't realise that people from a different background find it so hard. (Ruth 20.3.2015)

Ruth's ability to identify these connections and furthermore, to articulate them, demonstrates a degree of agency and self-management. Ryan (2015) proposes that the ability to make connections across different learning environments is fundamental when developing one's capacity to be reflective, a key aspect of lifelong learning. Ruth's response also resonates with the constructivist concepts of Bruner (1960) and the notion of building on existing knowledge in order to construct new knowledge. Although she recognises that classical turnout is a new idea for her, by associating classical turnout with the alignment of the legs in ballroom and Latin dancing, Ruth identifies an area of commonality, demonstrating that she has used her existing embodied knowledge to make sense of comparable movement concepts. Thus, it could be argued that my use of constructivist-orientated, enquirybased learning methods have perhaps contributed towards the development of such learning.

\section{Concluding thoughts}

This paper has presented the findings from a focus group discussion that was conducted at the end of a cycle of action research that explored the use of enquirybased learning approaches in first year undergraduate dance technique classes. The findings have been analysed by drawing upon Bourdieu's (1977) concept of 'doxa' to discuss perceptions and expectations of dance technique, both on the part of teacher and students. Analysis indicates that upon arriving at university, the students sampled in this paper had formed pre-conceived doxic understandings of dance technique, shaping their perceptions of how they were expected to behave in technique classes. Describing technique as being 'rigid' and 'set', the students appear to identify it as being distinct from other areas of dance education such as choreography and improvisation where, to borrow Sarah's term, 'you can't really go wrong'. The students perceive technique as being important for developing an understanding of one's own body and for the purposes of supporting choreographic 
work. Finally, by comparing their experiences across different classes, the students appear to perceive each teacher to have their own 'style' of teaching, requiring them to enter classes with 'different head[s] on'. These ideas have been discussed by exploring the possibility that together, teacher and students establish specific rules of engagement, requiring them to enter into an undisputed doxic agreement with each other.

Analysis of the responses given in the discussion reveal that the students were not as challenged by the EBL approaches as I had anticipated, and consequently the doxic understanding of dance technique largely remained intact. This demonstrates that my attempts to deconstruct the hierarchy between my students and me were perhaps not as effective as I had hoped. However, this first cycle of research was the beginning of a process of unpacking my own doxic understanding of dance technique, and therefore, it is possible that changing my teaching approach felt like more of a risk for me than the students. The iterative nature of action research has provided me with a framework within which I have become more confident to explore a range of teaching methods, not only from one cycle to the next, but also week-by-week.

Finally, the findings from this focus group have taught me that in order to really 'unravel the prevailing doxa' (Deer 2012, 118), all social agents must be enabled to reflexively consider their position; since teacher and students act within the field together, the teacher alone cannot change the culture of the dance technique class. In relation to a study that initially aimed to empower children through art education, dance scholar Anttila $(2007,44)$ speaks of her realisation that 'if a major shift in consciousness was to happen, the whole community would need to work toward these aims.' Thus, only through establishing a reciprocal and dialogic relationship between teacher and students can existing, pre-reflexive understandings of dance technique learning be explored and subsequently deconstructed, ultimately changing the dominant doxa. Such a process requires social agents to exercise a degree of agency and it must not be assumed that all students in fact want to exercise this right. The first year at university is a time when many transitions are occurring simultaneously, and thus it is entirely possible that some individuals may even find security in conforming to what they perceive as the 
accepted 'rules of the game'. As my research in this territory has progressed, I have endeavoured to be mindful of this possibility. Further research has revealed that by providing opportunities for students to enter into a dialogical relationship with each other and me, we can embark on a joint journey together whereby perceived cultural 'norms' can be questioned and potentially deconstructed through reflective and reflexive processes. As Etherington $(2004,32)$ writes of the reflexive researcher 'By viewing our relationship with participants as one of consultancy and collaboration we encourage a sense of power, involvement and agency.' Going forward, my research focuses on exploring methods for enabling and embedding this dialogical relationship within the specific context of dance technique learning.

Word count: 7196

\section{Notes on contributor}

Rachel Rimmer holds a BA (Community Arts and Dance) and an MA (Contemporary Arts) from Manchester Metropolitan University (MMU). She is currently undertaking a PhD in dance pedagogy. In order to develop this research, in September 2015 she was awarded a Scholarship of Teaching and Learning by the Centre of Excellence for Learning and Teaching at MMU. She is co-programme leader for the BA Hons Dance programme at Manchester Metropolitan University in Cheshire and a fellow of the Higher Education Academy.

\section{References}

Aceto, M. 2012. "Developing the dance artist in technique class: the alteration task." Journal of Dance Education 12(1): 14 - 20. 10.1080/15290824.2011.569296 [Taylor \& Francis online]

Alexander, R., J. Rose, and C. Woodhead. 1992. "Curriculum organisation and classroom practice in primary schools: a discussion paper." Education in England: Department of Education and Science. Retrieved from http://www.educationengland.org.uk/documents/threewisemen/threewisemen.html

Anttila, E. 2007. "Searching for dialogue in dance education: a teacher's story." Dance Research Journal Winter 2007: 39(2): 43 - 57. 10.1017/SO149767700000218 [Congress on Research in Dance]

Atkinson, P., A. Coffey, and S. Delamont. 2003. Key Themes in Qualitative Research: Continuities and Change. Oxford: AltaMira Press.

Bannon, F. 2010. "Dance: the possibilities of a discipline." Research in Dance Education 11(1): 49 - 59. 10.1080/14647890903568313 [Taylor \& Francis online]

Bourdieu, P. 1977. Outline of a Theory of Practice. Cambridge: Cambridge University Press.

Brookfield, S. 1995. Becoming a Critically Reflective Teacher. California: Jossey-Bass.

Bruner, J. 1960. The Process of Education. Cambridge, MA: Harvard University Press. 
Deer, C. 2012. “Doxa." In Pierre Bourdieu: Key Concepts (second edition) edited by M. Grenfell, 114 125. Abingdon: Routledge.

Diehl, I., and F. Lampert. eds. 2010. Dance Techniques 2010: Tanzplan Germany. Berlin: Henschel.

Dryburgh, J. and L. H. Jackson. 2016. "Building a practice of learning together: expanding the functions of feedback with the use of the flipchart in contemporary dance technique." Research in Dance Education 17(2): 130 - 144. 10.1080/14647893.2016.1139078 [Taylor \& Francis online]

Dyer, B. 2009. "Merging traditional technique vocabularies with democratic teaching perspectives in dance education: a consideration of aesthetic values and their sociopolitical contexts." Journal of Aesthetic Education 43(4): 108 - 123. 10.1353/jae.0.0056 [University of Illinois Press]

Dyer, B. 2010. "The perils, privileges and pleasures of seeking right from wrong: reflecting upon students perspectives of social processes, value systems, agency and the becoming of identity in the dance technique classroom." Research in Dance Education 11(2): 109 - 129.

10.1080/14647893.2010.482978 [Taylor \& Francis online]

Enghauser, R. 2007. “Developing listening bodies in the dance technique class: when you dance, what is your body telling you?" The Journal of Physical Education, Recreation and Dance 78(6): 33 - 54. 10.1080/07303084.2007.10598039 [Society of Health and Physical Educators (SHAPE) America]

Etherington, K. 2004. Becoming a Reflexive Researcher: Using Our Selves in Research. London: Jessica Kingsley.

Fortin, S. 1998. "Somatics: a tool for empowering modern dance teachers." In Dance, Power and Difference: Critical and Feminist Perspectives on Dance Education, edited by S. Shapiro, $49-71$. Champaign, IL: Human Kinetics.

Giguere, M. 2015. "Dance education action research: a twin study." Research in Dance Education 16(1): 16 - 32. 10.1080/14647893.2014.971231 [Taylor \& Francis online]

Graham Cagney, A. 2014. "Transformative Learning." In The SAGE Encyclopedia of Action Research, edited by D. Coghlan and M. Brydon-Miller, 789-794. Los Angeles: SAGE.

Green, J. 1999. "Somatic authority and the myth of the ideal body in dance education." Dance Research Journal 31(2): 80 - 100. 10.2307/1478333 [Congress on Research in Dance]

Hanstein, P. 1990. "Educating for the future - a post modern paradigm for dance education." Journal of Physical Education, Recreation and Dance 61(5): 56 - 58. 10.1080/07303084.1990.10604517 [Society of Health and Physical Educators (SHAPE) America]

Hershberg, R. 2014. “Constructivism." In The SAGE Encyclopedia of Action Research, edited by D. Coghlan and M. Brydon-Miller, 183 - 187. Los Angeles: SAGE.

Holland, F., and J. Elander. 2013. "What makes a good focus group? - Advanced qualitative methods." YouTube video by University of Derby. Retrieved from https://www.youtube.com/watch?v=XA2Eo1ggkjc (accessed 6.2.2017).

Hutchings, W. 2007. “Enquiry-based learning: definitions and rationale." University of Manchester: Centre of Excellence in Enquiry-Based Learning 'Resources' section. Retrieved from http://www.ceebl.manchester.ac.uk/resources/papers/hutchings2007_definingebl.pdf

Kimmerle, M., and P. Côté-Laurence. 2003. Teaching Dance Skills: A Motor Learning and Development Approach. Andover, NJ: J. Michael Ryan. 
Lord, M. 1981. "A characterisation of dance teacher behaviours in technique and choreography classes." Dance Research Journal 14(1/2): 15 - 24. 10.2307/1477944 [Congress on Research in Dance]

Marlowe, B., and M. Page. 1998. Creating and Sustaining the Constructivist Classroom. California: Corwin Press.

Maton, K. 2012. "Habitus." In Pierre Bourdieu: Key Concepts (second edition) edited by M. Grenfell, 48 -64. Abingdon: Routledge.

McAteer, M. 2013. Action Research in Education. London: SAGE.

Mezirow, J. 2009. Fostering Critical Reflection in Adulthood: A Guide to Transformative and Emancipatory Learning. California: Jossey - Bass.

Pickard, A. 2013. "Ballet body belief: perceptions of an ideal ballet body from young ballet dancers." Research in Dance Education. 14(1): 3 - 19. 10.1080/14647893.2012.712106 [Taylor \& Francis online]

Pickard, A. 2015. Ballet Body Narratives: Pain, Pleasure and Perfection in Embodied Identity. Bern: Peter Lang.

Råman, T. 2009. "Collaborative learning in the dance technique class." Research in Dance Education 10(1): 75 - 87. 10.1080/14647890802697247 [Taylor \& Francis online]

Rimmer, R. 2013. "Improvising with material in the higher education dance technique class: exploration and ownership." Journal of Dance Education 13(4): 143 - 146.

10.1080/15290824.2013.819978 [Taylor \& Francis online]

Ryan, M. E. ed. 2015. Teaching Reflective Learning in Higher Education: A Systematic Approach Using Pedagogic Patterns. London: Springer.

Schupp, K. 2010. "Bridging the gap: helping students from competitive dance training backgrounds become successful dance majors." Journal of Dance Education 10(1): 25 - 28.

10.1080/15290824.2010.10387155 [Taylor \& Francis online]

Smith, C. 1998. "On authoritarianism in the dance classroom." In Dance, Power and Difference: Critical and Feminist Perspectives on Dance Education, edited by S. Shapiro, 123 - 146. Champaign, IL: Human Kinetics.

Stanton, E. 2011. "Doing, re-doing and undoing: practice, repetition and critical evaluation as mechanisms for learning in a dance technique class 'laboratory'." Theatre, Dance and Performance Training 2(1): 86 - 98. 10.1080/19443927.2011.545253 [Taylor \& Francis online]

Stevens, J. 2006. "Re-thinking dance technique in higher education." Report from the Higher Education Academy Palatine seminar. November 29 ${ }^{\text {th }}$, De Montfort University, UK.

Stinson, S. 1993. "Journey towards a feminist pedagogy for dance." Women \& Performance: A Journal of Feminist Theory 6(1): 131 - 146. 10.1080/07407709308571170 [Taylor \& Francis online]

Tripp, D. 1993. Critical Incidents in Teaching: Developing Professional Judgement. London: Routledge. 